\title{
XFEM SIMULATION OF THE INFLUENCE OF CRACKING INTRODUCED BY PRE-LOADING ON THE STRENGTHENING OF A CEMENT TREATED MIXTURE
}

\author{
KAROL BRZEZIŃSKI \\ Warsaw University of Technology, Faculty of Civil Engineering, Institute of Roads and Bridges, Warsaw, Poland \\ e-mail: k.brzezinski@il.pw.edu.pl
}

\begin{abstract}
The paper attempts to explain the phenomenon of a static strength increase due to the previous cyclic loading. Finite Element Method simulation of the potential strengthening mechanism is presented. The crack growth is controlled by the energy criterion used in the linear fracture theory. A wedge splitting test has been performed in order to determine the critical energy release rate of the tested mixture $G_{I C}$. It was observed that the appearance of additional cracks in the material may lead to an increase of its strength. Analysis of the tensile stress distribution allows for a qualitative explanation of the observed phenomenon.
\end{abstract}

Keywords: fatigue life, cement-treated base layers, strengthening effect, load history, XFEM

\section{Introduction}

The fatigue strength is an important aspect of estimating durability of many types of structures subjected to cyclic loadings. Particularly, road pavement structures, which are often subject to many millions of load cycles, are designed with regard to their fatigue life. The modern approach to fatigue was initiated by Wöhler (1970). He measured fatigue strength as a feature of the material, so the number of load cycles that the structure can carry depends on the amplitude of the load. This dependency, presented later by his successor in the form of a graph, is known as the "Wöhler curve". By using such formulas, the number of constant amplitude load cycles causing destruction of the material can be estimated.

Taking into account variable amplitude loads requires additional assumptions about fatigue accumulation. The simplest theory, the so-called linear damage accumulation model, is the Palmgren-Miner hypothesis (Miner, 1945). Based on the assumptions of this theory, the durability of the structure does not depend on the order of the applied load with a variable amplitude. As shown in the literature, the impact of load history can be so significant that we overestimate or underestimate the fatigue life by up to 4 times (Bijak-Żochowski et al., 1999). Accurate assessment of the load amplitude order is the subject of many hypotheses (Brzeziński and Zbiciak, 2014; Fatemi and Yang, 1998; Marco and Starkey, 1954; Xi and Songlin, 2009; Zhao et al., 2014).

In particular, the results of the research conducted by Koba (2000) show that samples of cement-treated soil subjected to a pre-load exhibit a much higher fatigue strength. Furthermore, an increase in the static strength was also observed. Based on the above observations, the fatigue hypothesis has been developed. The hypothesis takes into account the impact of the history on the fatigue of cement-treated soils (Brzeziński and Zbiciak, 2014). In contrast to the previously mentioned criteria, the proposed hypothesis assumes that the static strength also varies due to the cyclic loading. This approach allows for the modeling of strengthening as well as the weakening of fatigue strength, depending on the applied preload. This hypothesis led to the onset of the research concerning changes in static strength of cement-treated mixtures used in road pavement structures (Brzeziński et al., 2017). 
This paper attempts to explain the phenomenon of static strength increasing by the previous cyclic loading. The change of the mechanical properties of the loaded sample is undoubtedly related to changes in the structure and microstructure of cementitious materials (e.g. cracks and micro-cracks). An effective method for detecting and locating the cracks within the sample is acoustic detection (Landis and Shah, 1995; Moczko, 1996, Ohtsu, 1996). Formation and merging of micro-cracks usually results in degradation of the material or even destruction of the structure. However, in some cases the increase in density of dislocation may be responsible for an increase in the fracture toughness (Ritchie, 1999). The knowledge of changes in the internal structure of the material allows for a better understanding of the investigated phenomena. However, a quantitative approach requires an appropriate research. In this work, Finite Element Analysis (FEM) analysis is used in order to explain how cracks formed during cyclic loading can cause strengthening of the sample.

\section{Microstructure changes under cyclic loads}

The change in static strength of a material as a result of the cyclic loading can be explained by transformation of its internal structure. This phenomenon is easier to observe and investigate in more homogeneous materials (e.g. metal alloys). In the case of composite materials, this is a much more difficult task. The internal structure is much more heterogeneous, and mechanical properties depend on characteristics of individual components and the ratio between them.

The polycrystalline grain structure is significantly different from crystal in its ideal form, which is due to numerous defects which significantly affect mechanical properties of the material. The analysis of the influence of dislocations on the mechanical properties of the material is promising. Especially, since dislocations may be introduced into the material by cyclic preloading. Due to their presence, the stress required to produce plastic deformation is $10^{3}-10^{4}$ times smaller than that of the ideal crystal (Wawszczuk, 2012). The energy supplied during the cyclic loading may turn into potential energy of misalignment. Furthermore, during long-term operation, the amount of dislocation may increase. Initially, it facilitates slipping. However, when the number of dislocations increases, they block each other, so that their movement (and hence the slip phenomenon) is impeded. In such a situation, strengthening is observed, in the case of metal alloys represented as the increase of the yield point (Moćko and Kowalewski, 2014). In brittle materials, such as cement-treated mixtures, different types of imperfections usually cause strength reduction. However, in some cases, the strengthening effect may occur. The strengthening mechanism at the dislocation level can be explained by the fact that they impede propagation and joining of micro-cracks by cutting the path of their potential development. In this way, they can eliminate critical cracks that would otherwise damage the structure.

The micro-cracks can have a similar influence on the material in the process of static strength changing. The accumulation of micro-cracks in the structure is usually causing weakening of the material because over time it merges into larger cracks and eventually results in destruction of the structure. On the other hand, differently oriented micro-cracks can make propagation of the dominant crack difficult, thus increasing the static or fatigue strength of the structure.

As mentioned above, observing such a phenomenon in the case of cement-bond materials is much more difficult due to heterogeneity of the structure. In addition, the critical element is the cement matrix which is a small part of the material volume. Therefore, the effects observed are much less marked. In spite of this, detection of dislocation motion in cement matrix materials is possible. Studies conducted by Kyriazopoulos et al. (2011) showed the possibility of detecting dislocation by recording the flow of small electrical charges generated in the material. Another method of observation of changes occurring inside the materials during load application is the method of acoustic detection (Landis and Shah, 1995; Moczko, 1996, Ohtsu, 1996). The energy 
released during micro-cracking or dislocation motion causes a sound wave propagating in the sample. The analysis of the signal recorded from several piezoelectric transducers located on the sample not only allows one to observe the moment of the micro-crack but also allows its localization as well as estimation of the size and direction of the slip plane.

The cracks caused by the cyclic loading may be involved in the mechanisms responsible for improving toughness of the material (Ritchie, 1999). Development of dominant cracks can be prevented if the crack tip encounters several interconnected micro-cracks. Then several crack tips are formed, which reduces the intensity factor of stresses. According to the linear fracture mechanics, based on Griffith's theory (Griffith, 1920; Prokopski, 2008), crack enlargement requires the work of forming a free surface of the crack within the body. Therefore, development of several cracks at the same time can be difficult because it requires more energy.

\section{Laboratory tests}

\subsection{Scope of the research}

The main part of the studies consists of the comparison of static strength of not pre-loaded samples and samples subjected to cyclic pre-loading. In these studies, a static change has been observed (even strengthening of the material). The preliminary results are presented in (Brzeziński et al., 2017). However, in this paper, only supplementary laboratory tests related to FEM analysis will be presented. They have been conducted in order to determine the fracture energy (critical energy release rate $G_{I C}$ ) of the tested material.

\subsection{Materials and preparation of samples}

Quartz sand of the standard grain size (PN-EN 196-1:2006) has been used to prepare the mix. The use of this type of aggregate was intended to ensure repeatability of tests and to increase accuracy of the analysis.

The cement used for the preparation was CEM I 42.5 R Portland cement. The mass content of the cement relative to sand was $10 \%$. The cement content in cement-bond soils should be between $4 \%$ and 10\% (Rafalski, 2007), so the amount of cement used could be considered as typical. In addition, tap water was used in the amount needed to achieve optimum moisture (determined by the Proctor test).

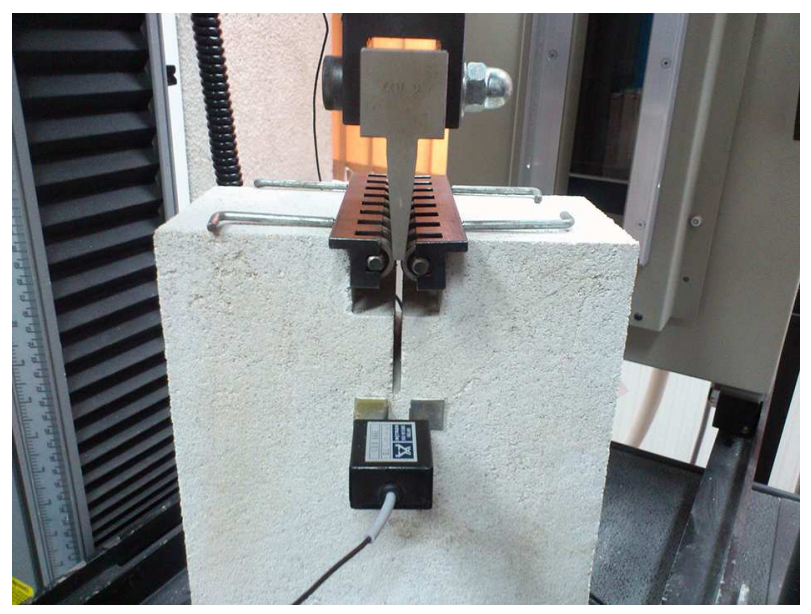

Fig. 1. Sample prepared for the Wedge Splitting Test

The primary objective of the Wedge Splitting Test (WST) is to determine the critical energy release rate $G_{I C}$ (Brühwiler and Wittmann, 1990; Löfgren et al., 2004). This parameter deter- 
mines the material susceptibility to cracking and corresponds to the energy dissipated during cracking of the material. The WST is commonly used for brittle materials such as concrete (Sitek et al., 2014). The test stand is shown in Fig. 1.

A sample of $20 \times 20 \mathrm{~cm} \times 10 \mathrm{~cm}$ rectangular shape was prepared with a proper cut allowing installation of a force application mechanism and a notch indicating the origin of the crack. Samples were made of the same mixture as the beams subjected to cyclic tests.

The wedge with an angle of $2 \xi=10^{\circ}$ was pushed with a constant velocity of $2 \mathrm{~mm} / \mathrm{s}$. The load was passed to the specimen via rollers located on the sides of the wedge. Every sample was subjected to a single load until it was destroyed. The vertical force $F$ and the Crack Opening Displacement (COD) were measured during the test.

\subsection{Laboratory test results}

The test result is usually illustrated as a graph of the dependence of the horizontal force on the COD. The area under the graph defines its work to open the cracks $W_{F}$. The critical energy release rate is given by

$$
G_{I C}=\frac{W_{F}}{A}
$$

where $W_{F}$ is the work of the force forming the crack $[\mathrm{J}], A$ - the area of the created crack surface $\left[\mathrm{m}^{2}\right]$.

The test was performed on 3 samples and then the results were averaged. In the FEM simulation, the average value of critical energy release rate $G_{I C}=50.12 \mathrm{~J} / \mathrm{m}^{2}$ was used.

\section{Potential strengthening effect simulation by FEM}

The analysis of microstructural mechanisms capable of explaining the changes in strength, in particular the strengthening effect, allows for a more comprehensive analysis and understanding of the phenomena studied. It can improve the effectiveness of the conducted research and also help one to draw additional conclusions useful in determining the future research goals.

The FEM was used in the analysis. The influence of additional cracks in the sample on the propagation delay of the dominant crack was investigated, which might be interpreted as an increase of the static strength. It should be emphasized that the analysis performed can be considered both as simulation of the strengthening or weakening mechanism of the material. In this case, the interpretation of what is strengthening and what is weakening depends on what cracks arrangement is adopted as the reference point. Nevertheless, in order to make the analysis more readable, the reference point is the simplest cracks arrangement (single crack in the middle of the sample), which is also most unfavorable considering the strength of the sample.

\subsection{Theoretical assumptions}

The FEM simulation has been performed with the Abaqus ${ }^{\circledR}$ program. Advanced modeling techniques such as eXtended Finite Element Method (XFEM) or Virtual Crack Closure Technique (VCCT) were used for this purpose. Therefore, before describing the model, the basic theoretical assumptions of the mentioned techniques and their implementation in the program will be presented.

The first concept of the XFEM application, a method for simulating cracks development independently from the model grid, was presented by Belytschko and Black (1999). In the following years, this method was developed and used in numerous applications (Remmers et al., 2008; Song et al., 2006) and also implemented in commercial software (ABAQUS, 2013). The 
idea of the method consists of enriching typical finite elements with additional shape functions that allow for discontinuity modeling and avoiding the singularity problem at the tip of the crack. The analysis is based on the linear fracture mechanics theory, so development of the crack is modeled in such a way that it propagates immediately throughout the finite element. For this reason, the above mentioned problem of singularity does not occur. The detailed description of this technique is given in (Dolbow and Belytschko, 1999).

Description of cohesive properties of the crack is the same as in the classical approach. It is based on the linear fracture theory proposed by Griffith (1920). In the VCCT criterion, deformation energy released during crack propagation by $\delta a$ is calculated by assuming that it is the same as the work required to close the crack.

The crack propagation occurs when the energy released in the VCCT procedure is greater than the critical value, which can be written as follows

$$
f=\frac{G_{I}}{G_{I C}}>1.0
$$

where $f$ is the condition of crack propagation, $G_{I C}$ - critical energy release rate, $G_{I}$ - energy release rate (the ratio of the released energy to the additional surface resulting from crack propagation).

When the XFEM elements are used, the crack propagation direction is independent of the mesh. Therefore, the criterion determining the crack propagation direction must be assumed. In this analysis, it is assumed that the crack will propagate perpendicular to the direction of the maximum tensile stress. These criteria require knowledge of the critical value of the energy release rate $G_{I C}$. It has been determined experimentally in the wedge splitting test.

The XFEM modeling technique is often referred to be as mesh independent. It should be understood that the course of the crack is not determined by the shape of the mesh. However, the solution is sensitive to size of the elements. First of all, this is obviously related to the accuracy of reflecting the state of stress in the structure. Less obvious is the impact resulting from the linear fracture mechanics. In the VCCT technique, which is used in the XFEM, the propagation of the crack occurs abruptly (each time in length determined by the mesh density). Thus, the size of the element corresponds with the characteristic crack length $a$, which is a component of the crack propagation criterion (Griffith, 1920). Therefore, the specified mesh density is not versatile. However, in the author's opinion, a mesh with a given characteristic density can be used to compare similar models with the same material.

\subsection{Geometry and parameters of the FEM model}

After conducting tests necessary to obtain characteristic material parameters of the mixture, a proper FEM model has been prepared. A 3-point bending strength test was performed. Geometry of the sample and the static scheme corresponding to the actual test were used. The load was applied in a kinematic manner. In the first simulation, the crack was applied at the bottom of the sample, at the most strained cross section. The load velocity was adjusted so that the result of the strength test simulation was similar to the results obtained in real test. Then, the effect of additional cracks occurrence on the resulting strength was analyzed.

In order to speed up the calculation, a plain stress condition was assumed. The model consisted of a small beam that was freely based on rounded supports, loaded from the top through a rounded loading nose. Geometrical invariability of the static system was ensured by boundary conditions and by defining contact between the elements (Fig. 2).

The loading nose moved in the vertical direction at a speed of $0.2 \mathrm{~mm} / \mathrm{s}$. The value of the loading force was calculated on the basis of vertical stresses in the supports. At each stage of simulation, at least one pre-fracture crack was placed at the bottom of the sample, in the most strained section. The enriched elements were used in a limited area because of practical reasons. 


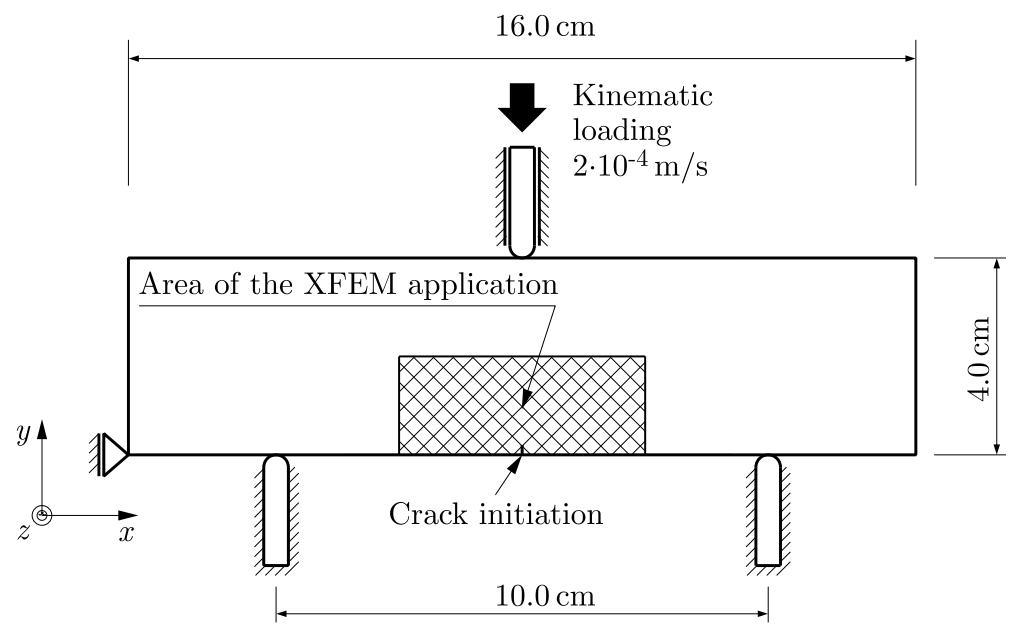

Fig. 2. The static scheme of the FEM model

Various crack configurations were adopted on the basis of the crack development presented in the paper (Landis and Shah, 1995). However, in the model crack configurations were simplified.

The linear elastic material model was applied in order to define constitutive properties of all elements. The applied values of material parameters are summarized in Table 1.

Table 1. Applied parameters of the materials

\begin{tabular}{|l|c|c|c|}
\hline \multicolumn{1}{|c|}{ Element } & Young's modulus [GPa] & Poisson's const. $[-]$ & $G_{I C}\left[\mathrm{~J} / \mathrm{m}^{2}\right]$ \\
\hline \hline Supports and nose & 210.00 & 0.30 & - \\
\hline Beam & 3.50 & 0.25 & 50.12 \\
\hline
\end{tabular}

\subsection{Simulation results}

The procedure of the analysis has been as follows. It was assumed that not pre-loaded elements were not cracked, so in the simulation only the initial crack was placed in the material. Therefore, in the strength test, the development of the dominant crack is not disturbed. On the other hand, in the case of pre-loaded samples, cracks and micro-cracks appeared, which might affect the development of the dominant crack. In many cases, the appearance of additional cracks might reduce the observed strength of the sample because destruction progressed easier by merging existing discontinuities. Sometimes, however, the crack propagation of the dominant crack might be difficult due to proximity to other cracks. Accordingly, the simulation of a single-cracked specimen strength test was treated as a benchmark. In the subsequent stages of analysis another crack was placed at the bottom of the sample at a distance of $4.0,5.0$ or $6.0 \mathrm{~mm}$. In addition, the results of triple fracture (two additional cracks symmetrically located at a distance of $6.0 \mathrm{~mm}$ from the base fracture) were also compared. Figure 3 shows exemplary results of the 3-point bending tests and the simulation result of this test in the basic variant (single crack).

From Fig. 3 it can be concluded that the first step of the simulation - the strength test modeling, was performed correctly. Both the slope of the pre- and post-destruction graphs, as well as the maximum value of the stress, are very similar. Further simulations were made by adding one or two cracks. The results are shown in Fig. 4. One can see that the strength increased in all cases. The maximum increase in strength was approximately $20 \%$ (in the case of an additional crack located at a distance of $4.0 \mathrm{~mm}$ ). 


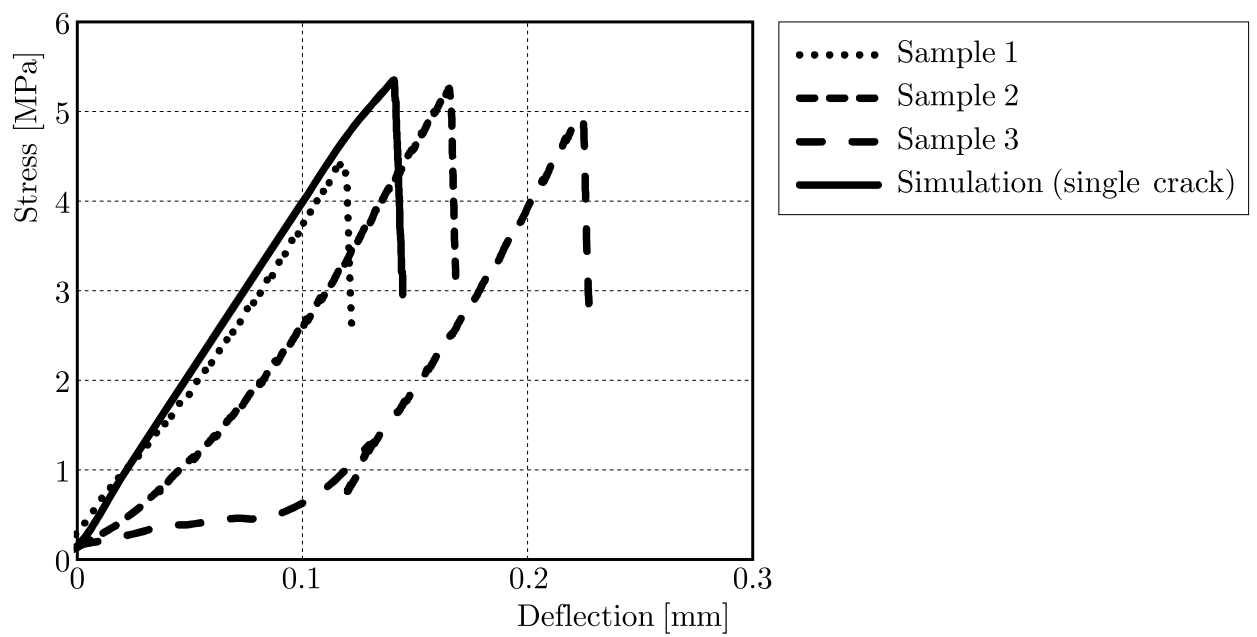

Fig. 3. Comparison of exemplary results of laboratory strength tests and FEM simulation of this test (3-point bending)
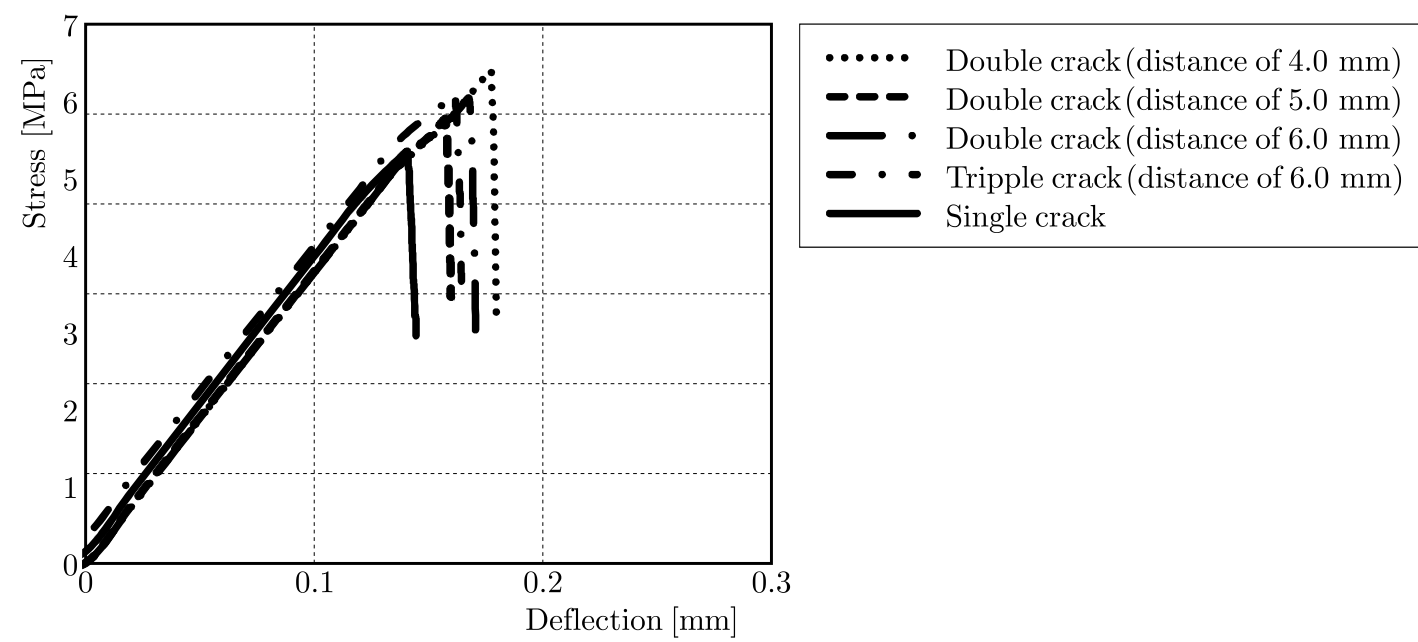

Fig. 4. Comparison of FEM simulation results of a strength test obtained by applying single pre-fracture and additional cracks at a distance of 4.0, 5.0 and $6.0 \mathrm{~mm}$

A more detailed analysis of the stress state in subsequent load phases (illustrated in Figs. 5 and 6) may allow for a better understanding of the observed phenomenon. In the case of the single crack, shown in Fig. 5, general conclusions regarding the effect of crack evolution on the stress distribution in the sample can be drawn. The appearance of the initial crack at a low level of the stress (about 50\%) results in reduction of the effective area of the cross-section. Certain stresses are carried between the crack edges until the critical crack mouth opening. It reflects the cohesive zone of interaction at the crack tip (Elfgren and Shah, 1991; Hillerborg, 1989). As the load increases, the gap widens until it stops carrying the stresses at all. It should be noted that the recorded force does not decrease immediately, at the time of initiation of cracks propagation. The crack is $6 \mathrm{~mm}$ long at the moment of the maximum stress.

The next figure (Fig. 6) shows a simulation with additional cracks located symmetrically at a distance of $6.0 \mathrm{~mm}$. The introduced cracks lead to redistribution of the internal forces in the loaded sample. The additional crack forms a peculiar "cover" of the dominant crack. This phenomenon reduces tensile stresses near the dominant crack and slows its propagation. Finally, this led to an increase in the measured strength by about $14 \%$. The development of the dominant crack is stopped and destruction is determined by propagation of one of the adjacent cracks. In all analyzed cases, the beneficial effect of the occurrence of additional cracks is observed. This is due to the fact that the reference is the single crack located in the most strained cross section. It 

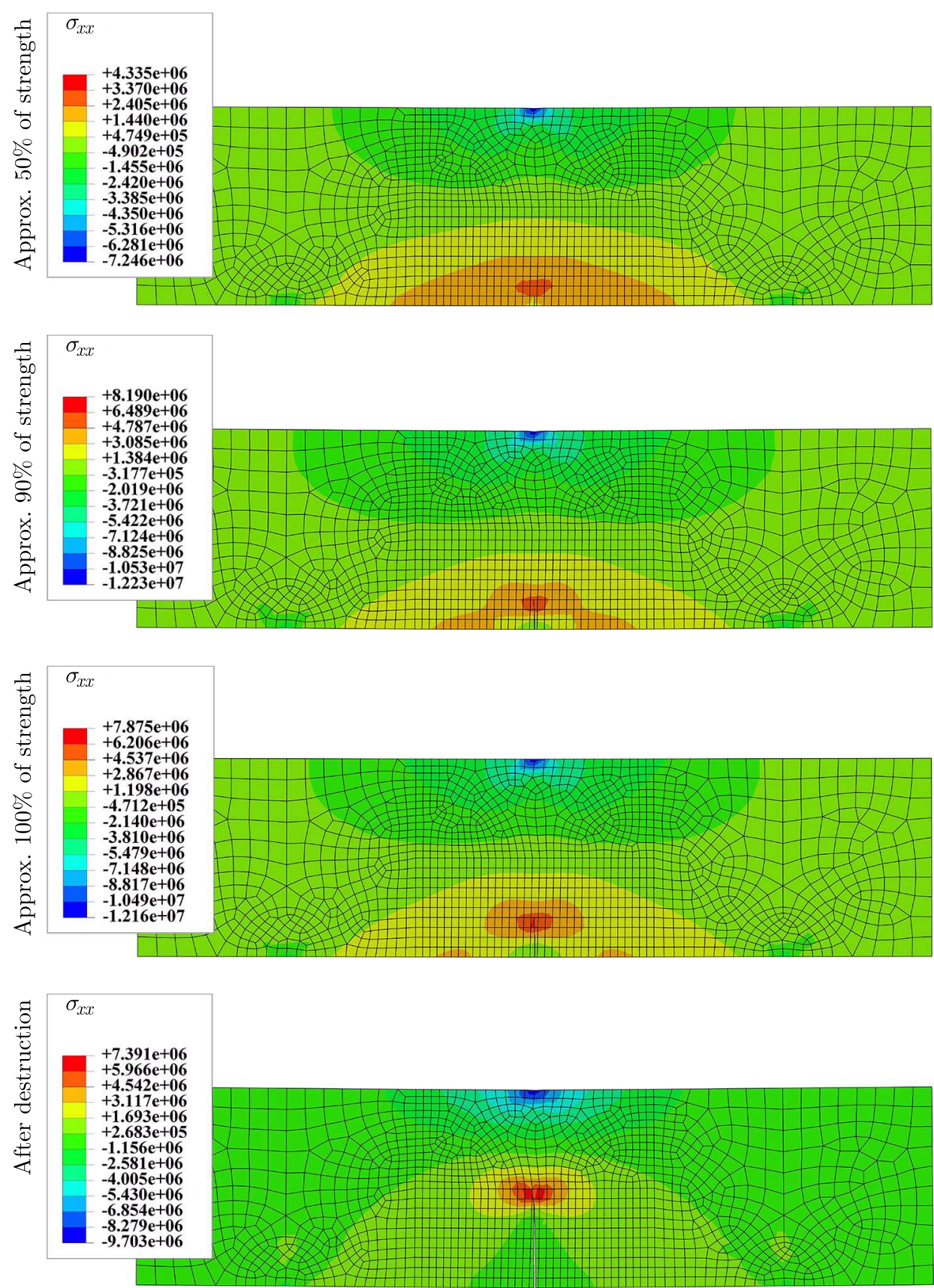

Fig. 5. Development of cracks in subsequent load phases - single cracked sample (displacement scaled 3 times)

should be noted that the maximum strengthening obtained in the simulation is approximately 2 times greater than that presented in (Brzeziński et al., 2017). In fact, some individual samples tested in the laboratory showed even more than $15 \%$ increase in strength. The results presented in (Brzeziński et al., 2017) have been already averaged to minimize the impact of random factors.

In order to compare stress rearrangement in different crack configurations, it is summarized in Fig. 7.

At the level of analysis it should be emphasized that the observed change of strength is a characteristic of the structure rather than the material. Nevertheless, in the phenomenological point of view, it manifests as strengthening of the material. In the case of both approaches, it is reasonable to assume that the observed increase in static strength can result into longer fatigue life. 

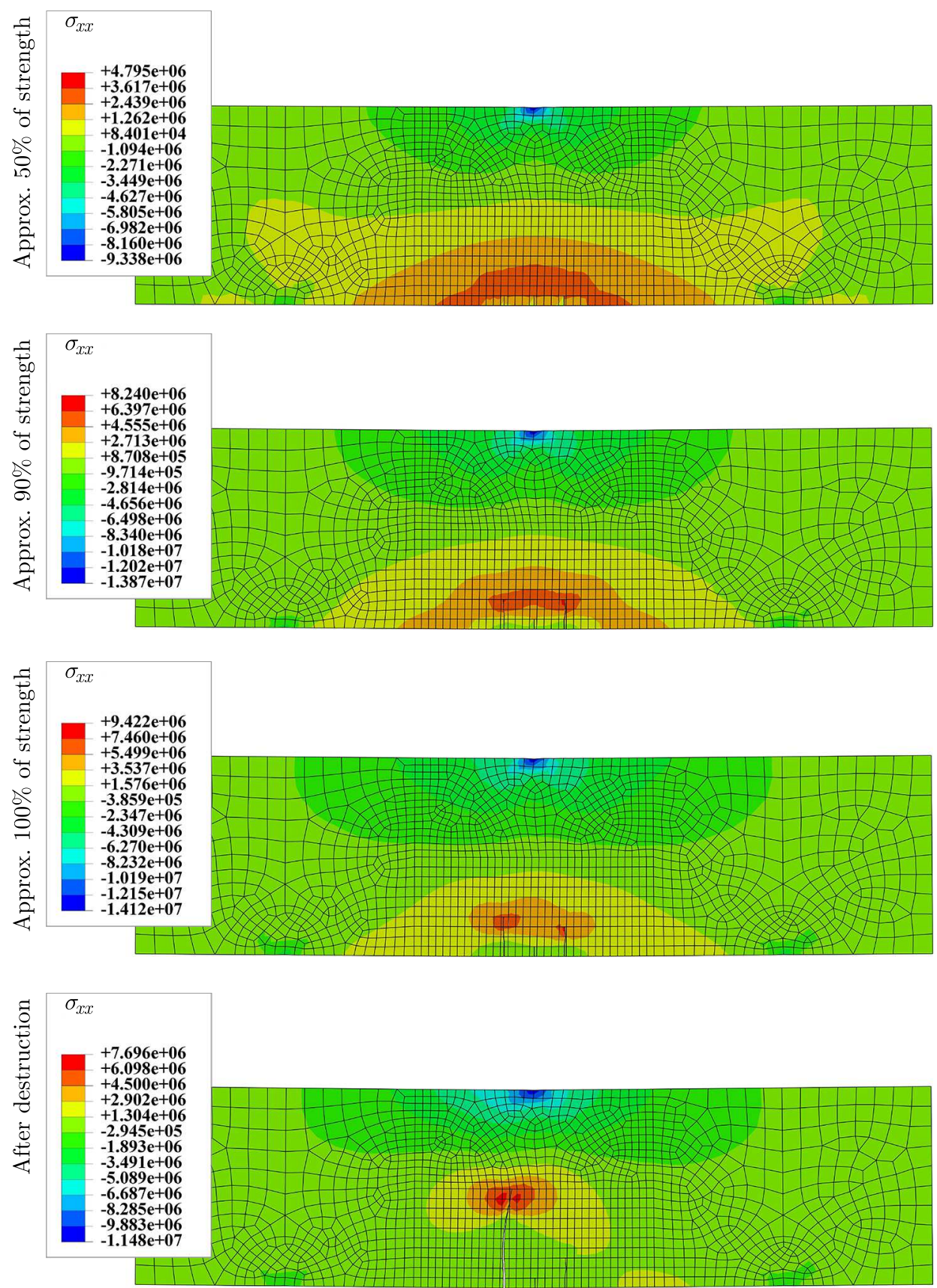

Fig. 6. Development of cracks in subsequent load phases - two additional cracks at a distance of $6.0 \mathrm{~mm}$ (displacement scaled 3 times)

\section{Conclusions}

In this paper, FEM simulation of the potential strengthening mechanism was presented. The analysis is strongly related to the theoretical considerations concerning structural changes of the material. It has been based on the modeling of the 3-point bending test performed in order to determine the strength of the material. The discontinuity modeling XFEM technique was used. The crack growth was controlled by the energy criterion used in the linear fracture theory. The implementation of the criterion in the Abaqus ${ }^{\circledR}$ program was based on the Virtual Crack Closure Technic (VCCT). In order to apply this criterion, it was necessary to know the critical energy release rate of the tested mixture $G_{I C}$. Therefore, a wedge splitting test (WST) was performed in order to determine the desired property of the material. 

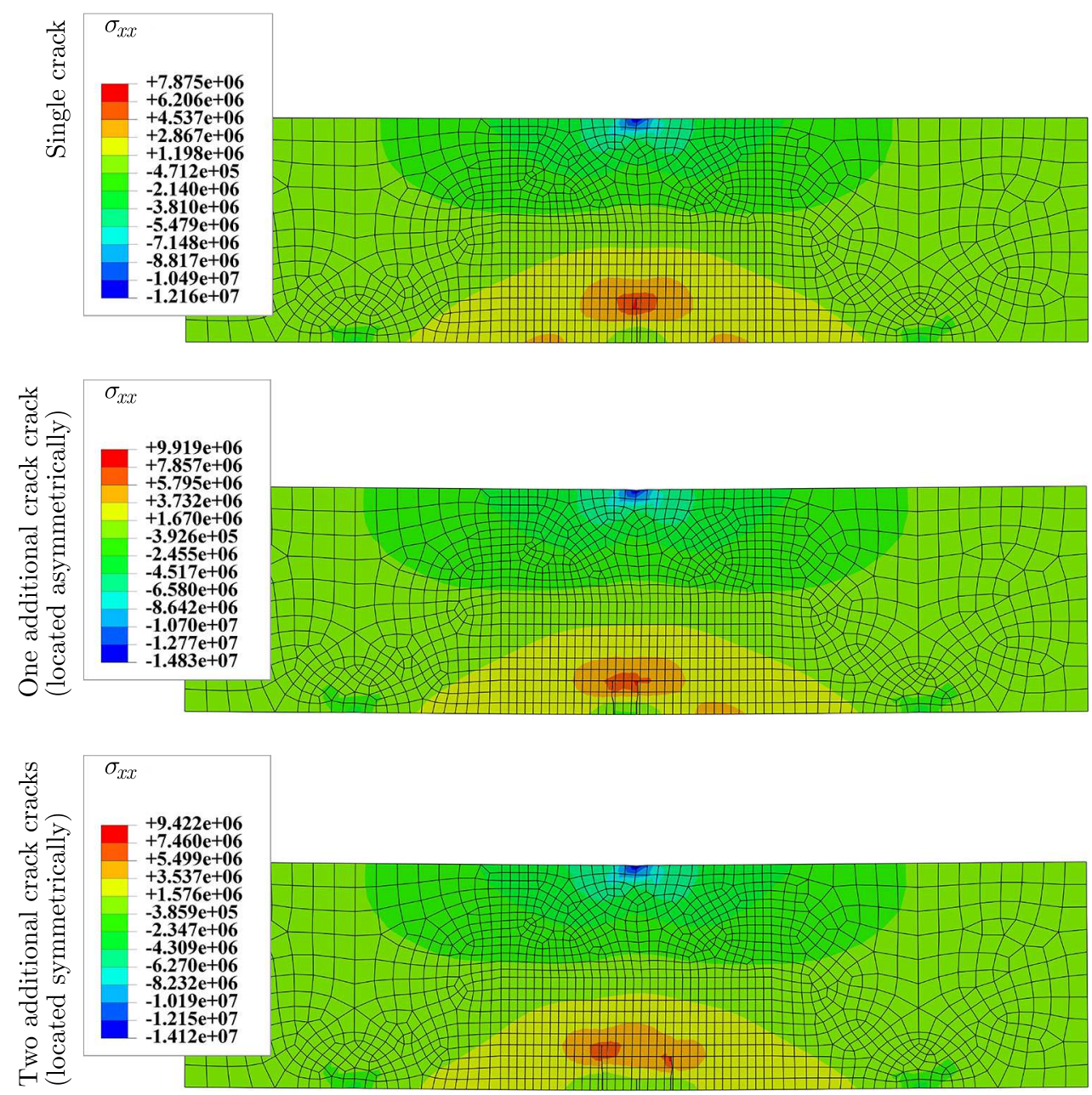

Fig. 7. Stress rearrangement near the crack tip at $100 \%$ level of effort in different crack configurations (displacement scaled 3 times)

During the simulation, it was observed that the appearance of additional cracks in the material before the start of the strength test (for example as a result of pre-loading) may lead to an increase in the maximum force required to destroy the sample. Analysis of the tensile stress distribution in the horizontal direction (approximately perpendicular to the crack) allows for a qualitative explanation of the observed strength increase. The additional crack, located outside of the most strained cross section, forms a "cover" of the dominant crack. The reduction of the tensile stress near the dominant crack slows its propagation. It should be emphasized that this is a characteristic of the structure rather than of the material itself. Nevertheless, in phenomenological terms, the result of the simulation, interpreted as a result of the 3-point bending test, indicates strengthening of the material.

\section{References}

1. ABAQUS Theory Manual, Ver. 6.13, 2013

2. Belytschko T., Black T., 1999, Elastic crack growth in finite elements with minimal remeshing, International Journal for Numerical Methods in Engineering, 45, 601-620

3. Bijak-Żochowski M., Jaworski A., Zagrajek T., 1999, Basics of Solid Mechanics (in Polish), Warsaw, Oficyna Wydawnicza Politechniki Warszawskiej 
4. Brühwiler E., Wittmann F.H., 1990, The wedge splitting test, a new method of performing stable fracture mechanics tests, Engineering Fracture Mechanics, 35, 1, 117-125

5. Brzeziński K., Adamczewski G., Tutka P., 2017, The influence of cyclic loading on the static strength of cement-bound sand - qualitative analysis, Roads and Bridges - Drogi i Mosty, 16, 1, 37-46, DOI: http://dx.doi.org/10.7409/rabdim.017.003

6. Brzeziński K., ZBiciak A., 2014, Influence of load history on fatigue life of cement treated soil (in Polish), Drogownictwo, LXIX, 9, 288-293

7. Dolbow J.O.H.N., Belytschko T., 1999, A finite element method for crack growth without remeshing, International Journal for Numerical Methods in Engineering, 46, 1, 131-150

8. Elfgren L., Shah S.P. (EDIt.), 1991, Analysis of Concrete Structure by Fracture Mechanics, London, Chapman and Hall

9. Fatemi A., YAng L., 1998, Cumulative fatigue damage and life prediction theories: a survey of the state of the art for homogeneous materials, International Journal of Fatigue, 20, 1, 9-34, ISSN 0142-1123, http://dx.doi.org/10.1016/S0142-1123(97)00081-9

10. Griffith A.A., 1920, The phenomena of rupture and flow in solids, Philosophical Transactions, Royal Society of London, Series A, 221, 163-198

11. Hillerborg A., 1989, Stability problems in fracture mechanics testing. Fracture of concrete and rock, [In:] Recent Developments, S.P. Shah, S.E. Swartz, B. Barr (edit), Amsterdam, Elsevier, $369-378$

12. Koba H., 2000, Durability of Road Pavements with Cement-Bound Sub-Base (in Polish), Wrocław, Oficyna Wydawnicza Politechniki Wrocławskiej

13. Kyriazopoulos A., Anastasiadis C., Triantis D., Brown C.J., 2011, Nondestructive evaluation of cement-based materials from pressure-stimulated electrical emission - preliminary results, Construction and Building Materials, 25, 4, 1980-1990, DOI: org/10.1016/j.conbuildmat.2010.11.053

14. LAndis E.N., Shah S.P., 1995, Experimental measurements of microfracture in cement-based materials, Fracture Mechanics of Concrete Structures, 315-328

15. Löfgren I., Stang H., Olesen J., Forbes O., 2004, Wedge splitting test-A test to determine fracture properties of FRC, [In:] 6th International RILEM Symposium on Fibre Reinforced Concretes, M. Di Prisco, R. Felicetti, G.A. Plizzari (edit.), RILEM Publications SARL, 1, 379-388

16. Marco S.M., Starkey W.L., 1954, A concept of fatigue damage, Transactions of ASME, 76 , 627-632

17. Miner M.A., 1945, Cumulative damage in fatigue, Journal of Applied Mechanics, 67A, 159-164

18. MoćKo W., Kowalewski Z.L., 2014, Evolution of tensile properties of the TIAL6V4 alloy due to the prior cyclic loading history, Journal of Theoretical and Applied Mechanics, 52, 847-851

19. Moczko A., 1996, Acoustic emission in concrete tests (in Polish), Inżynieria i Budownictwo, 1, $42-46$

20. Ohtsu M., 1996, The history and development of acoustic emission in concrete engineering, $M a-$ gazine of Concrete Research, 48, 321-330

21. PN-EN 196-1:2006 - Methods Of Testing Cement - Part 1: Determination Of Strength

22. Prokopski G., 2008, Mechanics of Cement Concretes Cracking (in Polish), Oficyna Rzeszów, Wydawnicza Politechniki Rzeszowskiej

23. Rafalski L., 2007, Road Subbases (in Polish), Warszawa, Instytut Badawczy Dróg i Mostów

24. Remmers J.J.C., De Borst R., Needleman A., 2008, The simulation of dynamic crack propagation using the cohesive segments method, Journal of the Mechanics and Physics of Solids, 56, $70-92$ 
25. Ritchie R. O., 1999, Mechanisms of fatigue-crack propagation in ductile and brittle solids, International Journal of Fracture, 100, 1, 55-83

26. Sitek M., Adamczewski G., Szyszko M., Migacz B., Tutka P., Natorff M., 2014, Numerical Simulations of a Wedge Splitting Test for High-Strength Concrete, Procedia Engineering, 91, 99-104, DOI: 10.1016/j.proeng.2014.12.021

27. Song J.H., Areias P.M.A., Belytschko T., 2006, A method for dynamic crack and shear band propagation with phantom nodes, International Journal for Numerical Methods in Engineering, 67, 868-893

28. WAWszczuK R., 2012, Self-stresses in polycrystalline materials and their variability during thermal processing (in Polish), PhD Thesis, Cracow, Faculty of Physics and Applied Computer Science AGH University of Science and Technology

29. WöHLER A., 1870, Über die Festigkeitsversuche mit Eisen und Stahl, Zeitschrift für Bauwesen, 20, 73-106

30. Xi L. Songlin Z., 2009, Strengthening and damaging under low-amplitude loads below fatigue limit, International Journal of Fatigue, 31, 2, 341-345

31. Zhao L., Zheng S., Feng J., 2014, Fatigue life prediction under service load considering strengthening effect of loads below fatigue limit, Chinese Journal of Mechanical Engineering, 27, 1178-1185

Manuscript received November 27, 2017; accepted for print February 1, 2018 